\title{
Sự hài lòng trong công việc, mối quan hệ với cam kết tổ chức và ý định nghỉ việc - Trường hợp các nhân viên kỹ thuật ngành dịch vụ cơ sở hạ tầng công nghệ thông tin
}

\section{The correlation among job satisfaction, organizational commitment and turnover intention - A case of technical staff in it infrastructure services sector}

\author{
Vũ Việt Hằng ${ }^{1 *}$, Nguyễn Văn Thông ${ }^{2}$ \\ ${ }^{1}$ Trường Đại học Mở Thành Phố Hồ Chí Minh, Việt Nam \\ ${ }^{2}$ Công ty TNHH Đầu Tư Phát Triển Công Nghệ Mới IDT, Việt Nam \\ *Tác giả liên hệ, Email: hang.vv@ ou.edu.vn
}

THÔNG TIN

DOI: $10.46223 / \mathrm{HCMCOUJS.}$

econ.vi.13.2.518.2018

Ngày nhận: 28/02/2018

Ngày nhận lại: 14/04/2018

Duyệt đăng: 16/04/2018

Tù̀ khóa:

cam kết tổ chức, dịch vụ hạ tầng công nghệ thông tin, hài lòng công việc, nhân viên kỹ thuật, ý định nghỉ việc

\section{TÓM TÁT}

Nghiên cứu được thực hiện nhằm xác định các yếu tố tác động đến sự hài lòng trong công việc và mối quan hệ giữa ba yếu tố Hài lòng công việc - Cam kết tổ chức - Ý định nghỉ việc của các kỹ thuật viên trong ngành dịch vụ hạ tầng. Nghiên cứu sơ bộ định tính được tiến hành nhằm điều chỉnh mô hình nghiên cứu đề xuất và thang đo. Nghiên cứu định lượng phân tích dữ liệu qua thống kê mô tả, kiểm định thang đo, phân tích EFA, kiểm định CFA, kiểm định mô hình lý thuyết SEM bằng phần mềm SPSS và $\mathrm{AMOS}$ đồng phiên bản 20. Có 6 yếu tố ảnh hưởng đến Hài lòng công việc, theo mức độ yếu dần: (1) Chi trả và phúc lợi, (2) Đào tạo và thăng tiến, (3) Căng thẳng công việc, (4) Điều kiện làm việc, (5) Bản chất công việc, (6) Sự hỗ trợ của cấp trên. Sự hài lòng công việc tác động thuận chiều tới Cam kết tổ chức và hai yếu tố này tác động ngược chiều đến Ý định nghỉ việc. Nghiên cứu cũng rút ra một số hàm ý quản trị có giá trị tham khảo cho các doanh nghiệp ngành dịch vụ hạ tầng công nghệ thông tin tại Thành phố Hồ Chí Minh, để tìm được các giải pháp tăng sự hài lòng công việc và cam kết tổ chức của nhân viên khối kỹ thuật, từ đó giảm thiểu tình trạng nghỉ việc, ổn định nhân sự, tăng sức cạnh tranh.

\section{ABSTRACT}

The study was conducted to determine the factors affecting Job satisfaction and the relationship among three factors Job satisfaction, Organizational commitment and Turnover intention of technical staff in the IT infrastructure services industry. 
Keywords:

organizational commitment, IT infrastructure services, job satisfaction, technical staff, turnover intention
Accordingly, preliminary qualitative research was conducted to adjust the proposed research model and scale. Then, quantitative research data were analyzed using descriptive statistics, testing the scales, analytical EFA, CFA testing, testing theoretical models with SPSS SEM (v.20) and AMOS (v.20). The study found six factors that affect Job satisfaction in descending order including (1) Pay and benefits, (2) Training and promotion, (3) Job stress, (4) Working conditions, (5) Job characteristics and (6) Supervisor support. Job satisfaction positively affects Organizational commitment while Job satisfaction and Organizational commitment negatively affect Turnover intention. The study also suggests some management implications of reference values for IT infrastructure services providers in HCM city to take measures to increase Job satisfaction and Organizational commitment of technical staff, reduce Turnover intention and enhance workforce stability and organizational competitiveness.

\section{1. Đặt vấn đề}

Hiện nay, tình trạng thiếu hụt nguồn nhân lực ngành Công nghệ thông tin (CNTT) ở Việt Nam đang ở mức báo động đỏ. Báo cáo của VietnamWorks (2015) cho thấy: nếu tiếp tục mức tăng trưởng nhân lực hiện tại, đến năm 2020, Việt Nam sẽ thiếu hụt hơn 500.000 nhân sự ngành Công nghệ thông tin. Cũng theo một kết quả khảo sát của VietnamWorks năm 2017, $40 \%$ nhân lực ngành này sẵn sàng thay đổi nơi làm việc nếu được trả lương và phúc lợi tốt hơn hiện tại.

Cơ sở hạ tầng (CSHT) CNTT là nền tảng vững chắc cho mọi hoạt động và các ứng dụng liên quan đến CNTT của một doanh nghiệp. Một hệ thống không ổn định hoặc bị ngắt quãng, dù trong một khoảng thời gian cực ngắn, cũng có thể gây ảnh hưởng nghiêm trọng tới hiệu quả kinh doanh của doanh nghiệp. Trong ngành, nhân viên kỹ thuật là những người trực tiếp thực hiện dịch vụ, mang lại giá trị cho khách hàng và lợi ích cho doanh nghiệp. Nếu lực lượng này nghỉ việc sẽ làm tăng chi phí, giảm hiệu suất hoạt động, ảnh hưởng nghiêm trọng đến lợi thế cạnh tranh, thậm chí cả sự sống còn của doanh nghiệp.

Trong ba thập kỷ qua, đã có nhiều nghiên cứu cho thấy Ý định nghỉ việc của nhân viên bị tác động bởi "Cam kết tổ chức" và "Hài lòng công việc". Trong lĩnh vực CNTT, cũng đã có nhiều nghiên cứu về Ý định nghỉ việc. Tuy nhiên, chưa có nghiên cứu nào đề cập đồng thời tới cả ba yếu tố: Hài lòng công việc, Cam kết tổ chức và Ý định nghỉ việc của nhân viên kỹ thuật trong lĩnh vực Dịch vụ hạ tầng CNTT.

Nghiên cứu này được thực hiện tại Thành phố Hồ Chí Minh (TP.HCM) trong năm 2017 với các mục tiêu cụ thể là: Xác định mức độ ảnh hưởng của các yếu tố đến sự Hài lòng trong công việc, của Hài lòng công việc đến Cam kết tổ chức, của Hài lòng công việc và Cam kết tổ chức đến Ý định nghỉ việc của các nhân viên kỹ thuật tại các công ty cung cấp dịch vụ hạ tầng 
CNTT. Kết quả nghiên cứu có thể giúp các doanh nghiệp thuộc lĩnh vực này tìm giải pháp tăng sự hài lòng của các nhân viên khối kỹ thuật, tăng cam kết đối với tổ chức, từ đó giảm thiểu tình trạng nghỉ việc, ổn định nhân sự, tăng sức cạnh tranh cho doanh nghiệp.

\section{Cơ sở lý thuyết và mô hình nghiên cứu}

\subsection{Một số khái niệm chính}

Nghỉ việc và ý định nghỉ việc

Theo Mobley (1982b), ý định nghỉ việc là sự tính toán chủ quan của một cá nhân về việc người này sẽ rời bỏ hay ở lại một tổ chức cụ thể trong tương lai gần. Trong hầu hết các nghiên cứu, ý định nghỉ việc thường được quan tâm nhằm ngăn chặn hoặc giảm thiểu ý định nghỉ việc của nhân viên và thay đổi được quyết định nghỉ việc của họ.

\section{Hài lòng công việc}

Theo Price và Mueller (1981), Hài lòng là mức độ mà người lao động có cảm nhận và định hướng tình cảm tích cực đối với công việc của mình. 32 năm sau, Robbins (2013) cũng nói "Hài lòng công việc là một cảm nhận tích cực về kết quả của một công việc qua việc đánh giá các đặc điểm của công việc đó”. Công việc ở đây được hiểu theo nghĩa rộng, bao gồm đăc điểm công việc, tiền lương, cơ hội thăng tiến, người giám sát, đồng nghiệp. Các định nghĩa này sẽ được sử dụng để hình thành thang đo mức độ hài lòng của nhân viên trong công việc.

\section{Cam kết tổ chức}

Robbins (2013) định nghĩa “Cam kết tổ chức thể hiện mức độ gắn bó chặt chẽ với tổ chức và các mục tiêu của tổ chức, luôn mong muốn duy trì tư cách thành viên trong tổ chức". Theo Allen và Meyer (1990), Cam kết tổ chức là một niềm tin vững chắc vào mục tiêu, giá trị của tổ chức và được đo lường bởi nhiều cách khác nhau.

\section{Đặc thù công việc của kỹ thuật viên ngành Cơ sở ha tầng CNTT}

Ngành CNTT bao gồm các lĩnh vực như phần cứng máy tính, phần mềm, điện tử, bán dẫn, Internet, viễn thông và thương mại điện tử. Trong đó, việc xây dựng, cung cấp các dịch vụ cơ sở hạ tầng CNTT đóng vai trò đặc biệt quan trọng. Cơ sở hạ tầng CNTT là một tập hợp các phần cứng, phần mềm, các hệ thống, cơ sở vật chất, để phát triển, kiểm tra, cung cấp, theo dõi, kiểm soát và hỗ trợ các dịch vụ CNTT. Đây chính là nền tảng vững chắc cho mọi hoạt động và các ứng dụng liên quan đến CNTT của một doanh nghiệp. Cụ thể, ngành này cung cấp các sản phẩm, dịch vụ lắp đặt, bảo trì, bảo hành hệ thống các thiết bị CNTT (Hệ thống máy chủ, tổng đài, cáp, ...) hoặc các CSHT đặc thù phục vụ cho hoạt động CNTT (Hệ thống chữa cháy bằng khí, hệ thống lạnh, UPS-hệ thống lưu điện, hệ thống cảnh báo, quản trị môi trường trung tâm dữ liệu, ...).

Các kỹ thuật viên ngành HT CNTT thường phải làm việc trong điều kiện đặc biệt khắc nghiệt: làm việc ngoài trời, trong phòng kín ít thoáng khí hoặc trong phòng server quá lạnh; làm việc trên cao hoặc trong hầm, tiếp xúc các hóa chất độc hại, bụi bẩn. Bên cạnh đó, họ phải chịu nhiều áp lực lớn: sự chính xác gần như tuyệt đối về mặt quy tắc, tiêu chuẩn yêu cầu, tiến độ công việc; thường xuyên tăng ca hoặc làm việc vào các ngày chủ nhật, thứ bảy; đi công tác xa. Sau một ngày làm việc căng thẳng, họ thường rất mệt mỏi về tinh thần và thể chất. 
Đại đa số các kỹ thuật viên trong ngành là nam giới. Họ thường khá cởi mở và thoái mái trong các mối quan hệ đồng nghiệp, không thích một công việc bị gò bó và quản lý quá khắt khe hoặc phải ngồi yên một chỗ. Đặc tính công việc kỹ thuật đòi hỏi họ phải nâng cao và không ngừng phát triển kỹ năng nghề nghiệp nếu muốn thăng tiến hoặc không muốn bị tụt hậu.

Các kỹ thuật viên trong ngành thường có điều kiện tiếp xúc với nhau do các doanh nghiệp lớn thường thuê lại các doanh nghiệp nhỏ hơn làm thầu phụ cho một phần công việc. Khi đó, họ sẽ có sự trao đổi, so sánh về nội dung công việc, thù lao, điều kiện môi trường làm việc, ... Từ đó, họ sẽ quan tâm và hướng đến những nơi có khả năng đáp ứng yêu cầu của mình, hoặc các tổ chức cần bộ phận quản lý, vận hành, bảo trì thiết bị tổng thể như ngân hàng, bệnh viện, các doanh nghiệp có hệ thống trung tâm dữ liệu lớn, ...

\subsection{Cơ sở lý thuyết}

Nghiên cứu được tiến hành dựa trên các lý thuyết nền sau:

Mô hình động cơ thúc đẩy của Porter và Lawler: sự hài lòng đến từ giá trị các đãi ngộ (vật chất và tinh thần) cũng như mức độ chắc chắn nhận được chúng.

Lý thuyết về đặc điểm công việc của Hackman và Oldman: Công việc có thể tạo nên sự thỏa mãn của người thực hiện nếu có 5 đặc điểm: đòi hỏi sự đa dạng về kỹ năng, được thực hiện trọn vẹn, có ý nghĩa, được tự chủ và mau chóng nhận được thông tin phản hồi.

Lý thuyết cam kết tổ chức của Allen và Meyer: Allen và Meyer (1990) đã phát triển khái niệm ba thành tố về cam kết tổ chức, trong đó đề cập đến cam kết vê tình cảm (affective commitment), cam kết liên tục (continuance commitment) và cam kết chuẩn mực (normative commitment).

Lý thuyết về quyết định nghi viẹc của Mobley: quá trình chuyển biến tâm lý của người lao động thể hiện qua một chuỗi các nhận thức và hành động dẫn tới ý định và quyết định nghỉ việc.

\subsection{Các công trình nghiên cúu liên quan}

Để thiết kế mô hình nghiên cứu, các tác giả còn dựa trên một số công trình nghiên cứu liên quan tới Hài lòng công việc, Cam kết tổ chức và Ý định nghỉ việc, đa số được thực hiện tại ngành CNTT trong và ngoài nước.

\section{Bảng 1}

Tóm tắt các công trình nghiên cứu liên quan

\begin{tabular}{|c|c|c|c|}
\hline $\begin{array}{l}\text { Số } \\
\text { TT }\end{array}$ & $\begin{array}{c}\text { Tên công trình nghiên } \\
\text { cứu }\end{array}$ & Tác giả & Kết quả nghiên cứu \\
\hline 1 & $\begin{array}{l}\text { Các yếu tố về ý định } \\
\text { nghề nghiệp cuia bác sỹ } \\
\text { ở Bệnh viện không quân } \\
\text { tại Mỹ (2005) }\end{array}$ & $\mathrm{Kim}$ & $\begin{array}{l}7 \text { biến tác động đến Hài lòng công việc, } \\
\text { trong đó, Đáp ứng kỳ vọng và Cảm xúc tích } \\
\text { cực có tác động dương mạnh nhất. } \\
\text { Hài lòng công việc, Đáp ứng kỳ vọng, } \\
\text { Cơ hội thể hiện có tác động dương, còn }\end{array}$ \\
\hline
\end{tabular}




\begin{tabular}{|c|c|c|c|}
\hline $\begin{array}{l}\text { Số } \\
\text { TT }\end{array}$ & $\begin{array}{c}\text { Tên công trình nghiên } \\
\text { cứu }\end{array}$ & Tác giả & Kết quả nghiên cứu \\
\hline & & & $\begin{array}{l}\text { Xung đột vai trò có tác động âm đến Cam } \\
\text { kết tổ chức } \\
\text { Hài lòng công việc và Cam kết tổ chức có } \\
\text { tác động âm đến Ý định nghỉ việc. }\end{array}$ \\
\hline 2 & $\begin{array}{l}\text { Sủ dụng mô hình Công } \\
\text { việc-Nhu cầu-Nguồn } \\
\text { lục để dụ đoán sự nghỉ } \\
\text { việc của lực lương lao } \\
\text { động ngành CNTT” } \\
\text { (2013) }\end{array}$ & $\begin{array}{l}\text { Hoonakker, } \\
\text { Carayon, } \\
\text { và Korunka }\end{array}$ & $\begin{array}{l}5 \text { biến tác động đến Hài lòng công việc, } \\
\text { trong đó Thử thách và Công bằng trong } \\
\text { khen thưởng có tác động dương mạnh nhất. } \\
\text { Cam kết tổ chức không có ý nghĩa trong các } \\
\text { mối quan hệ được nghiên cứu. }\end{array}$ \\
\hline 3 & $\begin{array}{l}\text { Các yếu tố ảnh hương } \\
\text { đến ý định nghỉ việc } \\
\text { của các chuyên gia } \\
\text { CNTT tại Thổ Nhĩ Kỳ } \\
\text { (2011) }\end{array}$ & $\begin{array}{l}\text { Calisir, } \\
\text { Gumussoy, } \\
\text { và Iskin }\end{array}$ & $\begin{array}{l}\text { Xung đột vai trò và Căng thẳng công việc } \\
\text { tác động âm tới sự hài lòng. } \\
\text { Xung đột công việc-gia đình tác động } \\
\text { dương mạnh nhât đến Căng thẳng công } \\
\text { việc. }\end{array}$ \\
\hline 4 & $\begin{array}{l}\text { Sự nghi viẹc của nhân } \\
\text { sụ ngành công nghệ } \\
\text { thông tin: Kiểm tra thục } \\
\text { nghiệm về sụ ảnh } \\
\text { hường của thái độ, đặc } \\
\text { điểm công việc và thị } \\
\text { truờng bên ngoài } \\
\text { (2002) }\end{array}$ & $\begin{array}{l}\text { Thatcher, } \\
\text { Stepina, và } \\
\text { Boyle }\end{array}$ & $\begin{array}{l}4 \text { yếu tố tác động đến Hài lòng công việc, } \\
\text { trong đó Ý nghĩa công việc còn tác động tới } \\
\text { cả Cam kết tổ chức. } \\
\text { Thái độ và nhận thức của lãnh đạo, Cam kết } \\
\text { tổ chức đều ảnh hưởng đến ý định nghỉ việc } \\
\text { của nhân viên CNTT. }\end{array}$ \\
\hline 5 & $\begin{array}{l}\text { Ảnh hương của sụ thỏa } \\
\text { mãn công việc đến dụ } \\
\text { định nghi việc của lao } \\
\text { động ngành CNTT tại } \\
\text { TP. HCM (2014) }\end{array}$ & Nguyen & $\begin{array}{l}4 \text { yếu tố tác động đến Sự thỏa mãn của nhân } \\
\text { viên. } \\
\text { Thỏa mãn công việc ảnh hưởng mạnh đến } \\
\text { Ý định nghỉ việc của nhân viên. }\end{array}$ \\
\hline
\end{tabular}

Nguồn: Kết quả phân tích dữ liệu của nhóm nghiên cứu

Trong mô hình nghiên cứu đề xuất, các yếu tố tác động tới Hài lòng công việc được thừa kế từ Nguyen (2014), có bổ sung biến Căng thẳng công việc của Calisir và cộng sự (2011). Mối quan hệ giữa Sự hài long công việc, cam kết tổ chức và Ý định nghỉ việc được thừa kế từ Kim, Price, Mueller, và Watson (1996), Hoonakker và cộng sự (2013), Calisir và cộng sự (2011), Thatcher và cộng sự (2002), Nguyen (2014). 


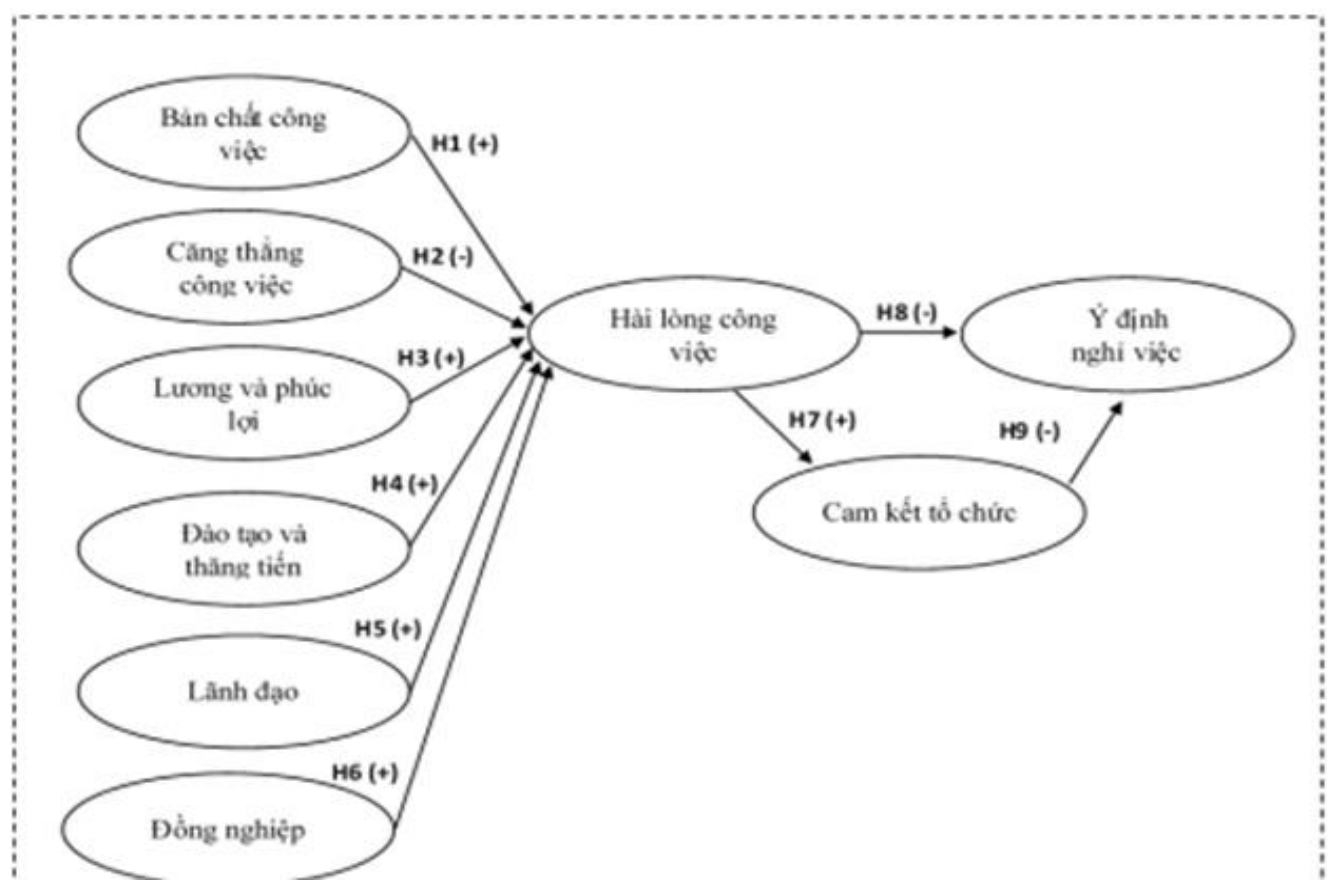

Hình 1. Mô hình nghiên cứu đề xuất

\section{Bản chất công việc và Hài lòng công việc}

Trong điều kiện Việt Nam, Tran (2005) cho rằng bản chất công việc thể hiện những thách thức của công việc, cơ hội sử dụng năng lực cá nhân và cảm nhận khi thực hiện công việc. Đã có nhiều nghiên cứu chỉ ra mối quan hệ dương giữa Bản chất công việc và Hài lòng công việc.

H1: Công việc càng có tính thách thức, sáng tạo và phù hợp với năng lục cá nhân thì Hài lòng công việc càng cao

\section{Căng thẳng trong công việc và Hài lòng công việc}

Theo Bidgoli, Moshref-Javadi, và Ayobi (2013), căng thẳng trong công việc được hiểu là phản ứng của một cá nhân với tính chất đe dọa của môi trường làm việc, do công việc quá tải, trách nhiệm không rõ ràng. Sự căng thẳng được coi là nhân tố chính trong việc làm giảm động lực, tinh thần làm việc cũng như năng suất của nhân viên. Kết quả nghiên cứu của Hoonakker và cộng sự (2013), Calisir và cộng sự (2011) cùng cho thấy Sự căng thẳng công việc có tác động trực tiếp đến Sự hài lòng công việc. Khi sức ép công việc quá lớn, sự Hài lòng của nhân viên về công việc thường sẽ giảm.

\section{H2: Sự căng thẳng trong công việc càng cao thì sự Hài lòng công việc càng thấp}

\section{Lương, thưởng, phúc lọi và Sự hài lòng công việc}

Lương, thưởng, phúc lợi là phần thu nhập chủ yếu ảnh hưởng trực tiếp đến mức sống của người lao động. Do đó, phấn đấu để có thu nhập cao là mục đích, là động lực để người lao động phát triển trình độ và khả năng lao động. Kim và cộng sự (1996), Hoonakker và cộng sự (2013), Thatcher và cộng sự (2002), Nguyen (2014) đều cho rằng sự không hài lòng với chế độ 
chi trả lương/thưởng, phúc lợi tại tổ chức luôn có tác động tiêu cực tới sự hài lòng công việc của nhân viên.

H3: Lương, thưởng, phúc lợi được chi trả càng hợp lý, công bằng thì sụ Hài lòng trong công việc càng cao

\section{Đào tạo - thăng tiến và Sụ̣ hài lòng}

Đã có nhiều nghiên cứu cho thấy việc đào tạo và thăng tiến cho nhân viên có tác động tích cực đến Sự hài lòng công việc (Kanwar, Singh, \& Kodwani, 2012; Kim et al., 1996; (Thatcher et al., 2002; Tran, 2005). Nhân viên có nhận thức tích cực về cơ hội được đào tạo, thăng tiến, được phát triển bản thân thì sẽ vượt qua được các trở ngại cũng như giảm áp lực trong công việc (Kim, 2005). Đặc biệt là tại các ngành nghề kỹ thuật, vấn đề đào tạo và thăng tiến càng quan trọng.

H4: Cơ hội đào tạo và thăng tiến càng nhiều thì sụ Hài lòng trong công việc càng cao

\section{Lãnh đạo và Sự hài lòng}

Một người lãnh đạo luôn được mong đợi là phải có năng lực, đối xử công bằng, khuyến khích phản hồi và công nhận sự đóng góp của nhân viên (Humphreys, 2002; Singh, 2000). Sự hỗ trợ từ cấp trên là trọng tâm chú ý của nhiều cuộc nghiên cứu (Podsakoff, MacKenzie, \& Bommer, 1996).

H5: Lãnh đạo càng quan tâm và công bằng thì sụ Hài lòng trong công việc càng cao

\section{Đồng nghiệp và Sự hài lòng}

Nói chung, nhân viên rất cần được sự phối hợp, hỗ trợ của đồng nghiệp trong công việc và cần tìm thấy sự thoải mái thân thiện khi làm việc với đồng nghiệp (Hill et al., 2008). Nguyen (2014) cho rằng, sự hỗ trợ của đồng nghiệp sẽ làm nhân viên hài lòng hơn, gia tăng hiệu quả làm việc và gắn bó với tồ chức hơn.

H6: Đồng nghiệp phối hợp và hỗ trọ trong công việc càng tốt thì sụ Hài lòng công việc càng cao

\section{Hài lòng công việc và Cam kết tổ chức}

Đã có nhiều nghiên cứu cho thấy có tác động tích cực của Hài lòng công việc đến Cam kết tổ chức như: Mobley (1982b), Kim và cộng sự (1996), Thatcher và cộng sự (2002), Calisir và cộng sự (2011). Năm 2013, Mowday, Poter, và Steers giới thiệu nghiên cứu về "Mối liên hệ giữa nhân viên-tổ chưc: Cam kết tâm lý, Sự vắng mặt, và nghi việc", trong đó chứng minh rằng sự hài lòng của nhân viên với công việc sẽ làm gia tăng sự cam kết, gắn bó của họ với tổ chức.

H7: Sụ hài lòng công việc càng cao thì Cam kết tổ chức càng cao

\section{Hài lòng công việc và Ý định nghỉ việc}

Theo Luddy (2005), nhân viên không có sự hài lòng về công việc sẽ khó có năng suất lao động cao, sức khỏe - cả về thể chất lẫn tinh thần - dễ bị ảnh hưởng. Nhân viên có sự hài lòng trong công việc sẽ ít đổi chỗ làm và ít nghỉ việc hơn. Nghiên cứu của Hoonakker và cộng sự (2013) về vấn đề nhảy việc trong ngành CNTT tại Mỹ cũng cho thấy Hài lòng công việc có 
tác động mạnh đến Ý định nghỉ việc. Kỳ vọng của bài nghiên cứu này là Sự hài lòng công việc có quan hệ nghịch biến với ở định nghỉ việc của nhân viên kỹ thuật ngành dịch vụ HT CNTT.

H8: Sụ hài lòng công việc càng cao thì Ý định nghỉ việc càng thấp

\section{Cam kết tổ chức và Ý định nghỉ việc}

Có mối quan hệ nghịch chiều khá rõ giữa sự vắng mặt, nghỉ việc của nhân viên và cam kết tổ chức (Calisir et al., 2011). Theo Baroudi (1985) Cam kết tổ chức ảnh hưởng rất nhiều đến quyết định nghỉ việc của nhân viên. Nghiên cứu về ngành CNTT của Ấn Độ của Kanwar và cộng sự (2012), Raman (2013), nghiên cứu của Hoonakker và cộng sự (2013) về ngành CNTT tại Mỹ cũng cho kết quả là Cam kết tổ chức thường đóng vai trò trung gian giữa Hài lòng công việc và Ý định nghỉ việc.

H9: Sự cam kết tổ chức càng cao thì Ý định nghi việc càng thấp

\section{Bảng 2}

Nguồn gốc của các thang đo đề xuất

\begin{tabular}{|c|l|c|l|}
\hline STT & \multicolumn{1}{|c|}{ Các yếu tố } & $\begin{array}{c}\text { Số biến } \\
\text { quan sát }\end{array}$ & \multicolumn{1}{|c|}{ Nguồn } \\
\hline 1 & Bản chất công việc (JC) & 4 & $\begin{array}{l}\text { Tran (2005) được Nguyen (2014) trích sử } \\
\text { dụng. }\end{array}$ \\
\hline 2 & Căng thẳng công việc (JS) & 5 & $\begin{array}{l}\text { Firth và cộng sự (2004) được Calisir và cộng } \\
\text { sự (2011) trích sử dụng. }\end{array}$ \\
\hline 3 & Lương và phúc lợi (PB) & 7 & $\begin{array}{l}\text { Tran (2005) được Nguyen (2014) trích sử } \\
\text { dụng. }\end{array}$ \\
\hline 4 & Đào tạo và Phát triển (TD) & 6 & $\begin{array}{l}\text { Tran (2005) được Nguyen (2014) trích sử } \\
\text { dụng. }\end{array}$ \\
\hline 6 & Lãnh đạo (SS) & 7 & $\begin{array}{l}\text { Tran (2005) được Nguyen (2014) trích sử } \\
\text { dụng. }\end{array}$ \\
\hline 7 & Camg kết tổ chức (OC) & 5 & $\begin{array}{l}\text { Tran (2005) được Nguyen (2014) trích sử } \\
\text { dụng }\end{array}$ \\
\hline 8 & Hài lòng công việc (JS) & 8 & $\begin{array}{l}\text { Firth và cộng sự (2004) được Calisir và cộng } \\
\text { sự (2011) trích sử dụng. } \\
\text { cộng sự (2011) trích sử dụng. }\end{array}$ \\
\hline 9 & Ý định nghỉ việc (TI) & 3 & Thatcher và cộng sự (2002); Nguyen (2014) \\
\hline
\end{tabular}

Nguồn: Kết quả phân tích dữ liệu của nhóm nghiên cứu

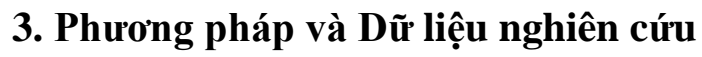

\subsection{Nghiên cúu định tính}

Đối tượng thảo luận nhóm là tám nhân viên lâu năm trong khối kỹ thuật. Dàn ý thảo luận được thiết kế dựa trên các giả thuyết, từ đó điều chỉnh mô hình nghiên cứu và thang đo 
cho phù hợp với thực tế. Ba người tham gia phỏng vấn sâu là một trưởng phòng nhân sự, một trưởng phòng kỹ thuật và một giám đốc làm việc trong ngành. Phỏng vấn sâu được thực hiện để xác định và giải quyết một cách cụ thể hơn các vấn đề phát sinh trong quá trình thảo luận nhóm, từ đó, có thể phát triển thêm các giả thuyết nghiên cứu, tìm hiểu thêm các biến ảnh hưởng.

Qua thảo luận nhóm và phỏng vấn sâu, một biến độc lập tác động tới Hài lòng công việc đã được bổ sung, đó là "Điều kiện làm việc" với thang đo được thừa kế từ Tran (2005):

H10: Điều kiện làm việc có tác động tích cực đến Sụ hài lòng công việc của nhân viên

Biến Lương và phúc lợi được điều chỉnh thành Chi trả và phúc lợi. Hai biến Lãnh đạo và Đồng nghiệp được đề nghị đổi thành Sư hỗ trợ của cấp trên và Sụ hố trợ của đồng nghiệp. Một biến quan sát để đo lường biến Căng thẳng công việc được bổ sung; 15 biến quan sát được đề nghị loại bỏ vì trùng lắp hoặc không hợp. Một số từ ngữ trong thang đo cũng được điều chỉnh lại cho phù hợp hơn với ngành nghề, tính chất công việc và trình độ đối tượng khảo sát.

\section{Bảng 3}

Thang đo sau khi điều chỉnh

\begin{tabular}{|c|c|}
\hline Ký hiệu & Thang đo điều chỉnh \\
\hline $\mathrm{JC}$ & Bản chất công việc \\
\hline $\mathrm{JC} 1$ & $\begin{array}{l}\text { - Công việc của Anh/Chị cho phép Anh/Chị sử dụng tốt năng lực và kiến thức } \\
\text { của bản thân }\end{array}$ \\
\hline $\mathrm{JC} 2$ & $\begin{array}{l}\text { - Anh/Chị được kích thích và khuyến khích sự sáng tạo trong thực hiện công } \\
\text { việc }\end{array}$ \\
\hline JC3 & - Công việc của Anh/Chị có tính chất thử thách \\
\hline JC4 & - Công việc hiện tại của Anh/Chị rất thú vị \\
\hline JSt & Căng thẳng trong công việc \\
\hline JSt1 & - Anh/Chị cảm thấy cảm xúc bị tệ hơn khi thực hiện công việc \\
\hline JSt2 & - Anh/Chị cảm thấy căng thẳng trong công việc của Anh/Chị \\
\hline JSt3 & $\begin{array}{l}\text { - Các vấn đề liên quan đến công việc của Anh/Chị khiến Anh/Chị khó ngủ vào } \\
\text { ban đêm. }\end{array}$ \\
\hline $\mathrm{JSt} 4$ & $\begin{array}{l}\text { - Anh/Chị phải duy trì sự tập trung cao độ để tránh các nguy hiểm có thể xảy } \\
\text { ra khi thực hiện công việc (bổ sung từ nghiên cứu định tính) }\end{array}$ \\
\hline PB & Chi trả và Phúc lọii \\
\hline PB 1 & $\begin{array}{l}\text { - Anh/Chị có thể sống hoàn toàn dựa vào thu nhập từ công việc của Anh/Chị } \\
\text { tại công ty }\end{array}$ \\
\hline PB2 & $\begin{array}{l}\text { - Tiền lương mà Anh/Chị nhận được tương xứng với kết quả làm việc của } \\
\text { Anh/Chị }\end{array}$ \\
\hline PB3 & - Anh/Chị hài lòng với chế độ lương thưởng hiện tại của công ty \\
\hline PB4 & - Các chương trình phúc lợi của công ty đa dạng và phù hợp \\
\hline
\end{tabular}




\begin{tabular}{|c|c|}
\hline Ký hiệu & Thang đo điều chỉnh \\
\hline PB5 & - Anh/Chị đánh giá cao các chương trình phúc lợi của công ty \\
\hline TD & Đào tạo và Thăng tiến \\
\hline TD1 & - Anh/Chị có các kỹ năng cần thiết để thực hiện tốt công việc \\
\hline TD2 & $\begin{array}{l}\text { - Anh/Chị được tham gia những chương trình đào tạo theo yêu cầu của công } \\
\text { việc }\end{array}$ \\
\hline TD3 & - Anh/Chị cảm thấy công tác đào tạo của công ty là có hiệu quả tốt \\
\hline TD4 & - Anh/Chị có nhiều cơ hội để thăng tiến tại công ty \\
\hline TD5 & - Chính sách thăng tiến, khen thưởng của công ty là công bằng và rõ ràng \\
\hline SS & Hỗ trọ̣ của cấp trên \\
\hline SS1 & - Anh/Chị nhận được sự hỗ trợ của cấp trên khi cần thiết \\
\hline SS2 & - Cấp trên hỏi ý kiến khi có vấn đề liên quan đến công việc của Anh/Chị \\
\hline SS3 & - Cấp trên khuyến khích Anh/Chị tham gia ra các quyết định quan trọng \\
\hline SS4 & - Anh/Chị biết nhận xét của cấp trên về mức độ hoàn thành công việc \\
\hline PS & Hỗ trọ’ của đồng nghiệp \\
\hline PS1 & - Mọi người hợp tác để làm việc \\
\hline PS2 & - Mọi người đối xử thân thiết, thoải mái \\
\hline PS3 & - Mọi người tôn trọng và tin cậy lẫn nhau trong công việc \\
\hline PS4 & - Tất cả đều có tinh thần trách nhiệm cao \\
\hline WC & Điều kiện làm việc \\
\hline WC1 & - Thời gian bắt đầu và kết thúc làm việc hiện tại của công ty là phù hợp \\
\hline WC2 & - Tôi không phải làm thêm giờ quá nhiều \\
\hline WC3 & $\begin{array}{l}\text { - Công ty cung cấp đầy đủ các phương tiện máy móc và thiết bị phục vụ } \\
\text { cho công việc }\end{array}$ \\
\hline WC4 & - Nơi làm việc hiện tại đảm bảo được tính an toàn và thoải mái \\
\hline WC5 & - Môi trường làm việc sạch sẽ, đảm bảo vệ sinh \\
\hline $\mathbf{O C}$ & Cam kết tổ chức \\
\hline OC1 & - Anh/Chị sẽ làm việc chăm chỉ để giúp công ty thành công \\
\hline OC2 & - Anh/Chị tự hào khi làm việc cho công ty \\
\hline OC3 & - Anh/Chị tự thấy không mấy trung thành với công ty (R) \\
\hline OC4 & - Anh/Chị nói về công ty như một nơi tuyệt vời để làm việc \\
\hline OC5 & - Anh/Chị thật sự e sợ về số phận của công ty đang làm việc ® \\
\hline JS & Hài lòng công việc \\
\hline JS1 & - Anh/Chị sẽ mô tả công việc hiện tại như một công việc hấp dẫn \\
\hline JS2 & $\begin{array}{l}\text { - Anh/Chị sẽ mô tả công việc hiện tại của Anh/Chị như một thói quen nhàm } \\
\text { chán lặp đi lặp lại (R) }\end{array}$ \\
\hline JS3 & - Anh/Chị sẽ mô tả công việc hiện tại của Anh/Chị rất tốt \\
\hline JS4 & $\begin{array}{l}\text { - Anh/Chị sẽ mô tả công việc hiện tại của Anh/Chị như một cảm giác thành } \\
\text { công }\end{array}$ \\
\hline
\end{tabular}




\begin{tabular}{|c|c|}
\hline Ký hiệu & \multicolumn{1}{|c|}{ Thang đo điều chỉnh } \\
\hline JS5 & - Anh/Chị sẽ mô tả công việc hiện tại của Anh/Chị như một công việc hữu ích \\
\hline TI & \multicolumn{1}{|c|}{ Yịnh nghỉ việc } \\
\hline TI1 & - Anh/Chị có ý định nghỉ việc \\
\hline TI2 & - Anh/Chị thường nghĩ về sự nghỉ việc \\
\hline TI3 & - Anh/Chị muốn tìm một công việc mới nếu có cơ hội \\
\hline
\end{tabular}

Nguồn: Kết quả phân tích dữ liệu của nhóm nghiên cứu

\subsection{Nghiên cứu định lugọng}

Thang đo Likert 5 mức độ được sử dụng với số biến quan sát là 44 . Số phiếu khảo sát thu được tối thiểu (n) phải là: $44 \times 5=220$ phiếu, với phương pháp chọn mẫu thuận tiện. Bảng khảo sát được chuyển trực tiếp cho các nhân viên kỹ thuật hoặc qua email. Số liệu được xử lý bằng phần mềm SPSS phiên bản 20 , Amos phiên bản 20 qua 2 giai đoạn:

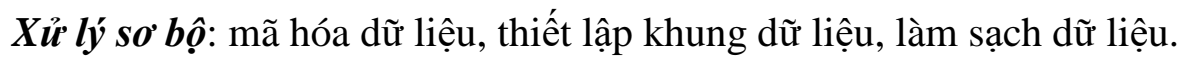

Phân tích dĩ liệu: Thống kê mô tả mẫu và kết quả; Đánh giá độ tin cậy thang đo qua hệ số Cronbach's Alpha và hệ số tương quan biến tổng; Phân tích nhân tố khám phá EFA để kiểm tra giá trị hội tụ, giá trị phân biệt của thang đo; Kiểm định $\mathrm{KMO}$ để kiểm tra sự phù hợp của kích thước mẫu trong phân tích nhân tố; Phân tích nhân tố khẳng định CFA để khẳng định lại tính đơn biến, đa biến, giá trị hội tụ và phân biệt của toàn bộ thang đo; Phân tích mô hình cấu trúc tuyến tính SEM để kiểm định mô hình nghiên cứu đề xuất, chỉ rõ mối quan hệ giữa các biến tiềm ẩn và kiểm định các giả thuyết; Kiểm định Bootstrap để đánh giá độ tin cậy của các ước lượng.

\section{Kết quả nghiên cứu}

Các biến có giá trị trung bình từ 2,351 đến 3,807 , trong đó Hài lòng công việc và Cam kết tổ chức là tương đối thấp, Ý định nghỉ việc lại tương đối cao. Đó là những thông tin ban đầu cho thấy nhân viên kỹ thuật trong ngành ít hài lòng với công việc hiện tại và mức cam kết với tổ chức còn thấp, đã có những người nghĩ đến việc rời khỏi tổ chức.

Cronbach's Alpha của hầu hết các thang đo đều lớn hơn 0,7 ; Hệ số tương quan biếntổng của các biến quan sát lớn hơn 0,3 . Riêng 2 thang đo Sự hỗ trợ của cấp trên và Sự hỗ trợ của đồng nghiệp có hệ số Cronbach's Alpha chưa bằng 0,7 nên phải loại bỏ biến quan sát và kiểm định lại mới đạt độ tin cậy. 42 biến được đưa vào phân tích nhân tố khám phá EFA.

Phân tích EFA hai lần với phương pháp trích "Principal axis factoring" và phép xoay "Promax", thêm 1 biến bị loại. Có 10 nhân tố được rút trích từ 41 biến quan sát, tổng phương sai trích được 60,552\%. Hệ số KMO là 0,908 , mức ý nghĩa sig của kiểm định Bartlett là 0.00 . Giá trị Eigenvalues của nhân tố lớn hơn 1 và hệ số tải nhân tố của các biến quan sát đều lớn hơn 0,5 .

Kết quả CFA cho thấy các trọng số chuẩn hóa của thang đo đều cao $(>0,5)$ và đều có ý nghĩa thống kê (P-value $=0.000)$ nên các khái niệm đạt được giá trị hội tụ (Gerbing \& Anderson, 1988). 
Mô hình đo lường phù hợp với dữ liệu thị trường, không có trường hợp các sai số của các biến quan sát có tương quan với nhau, do đó tập biến quan sát đạt được tính đơn nguyên. Các thang đo đạt được tiêu chuẩn về độ tin cậy và phương sai trích $(\rho \mathrm{c}>0,5 ; \rho \mathrm{vc}>0,5)$. Riêng hệ số Độ tin cậy tổng hợp của PS là 0,495 gần bằng 0,5 nên chấp nhận.

Hệ số tương quan giữa các biến và độ lệch chuẩn kèm theo cho thấy $\mathrm{P}$-value $<0,05$ (bác bỏ giả thuyết $\mathrm{H} 0$ ). Hệ số tương quan giữa các biến bằng 1 , ở độ tin cậy $95 \%$, vì vậy các hệ số này nhỏ hơn 1 (có ý nghĩa thống kê) và tất cả các biến đều đạt giá trị phân biệt.

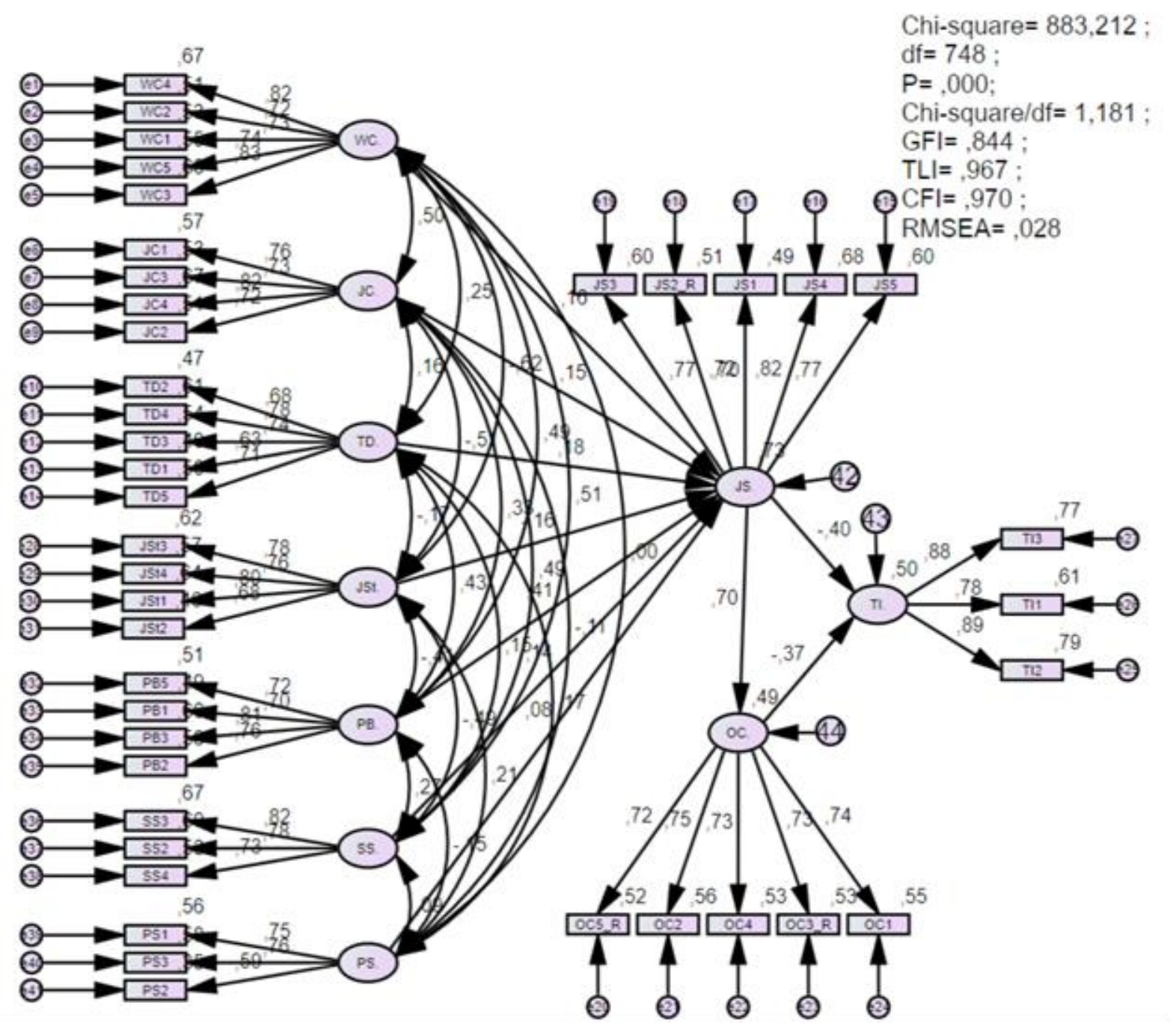

Hình 2. Kiểm định mô hình lý thuyết (chuẩn hóa)

Nguồn: kết quả phân tích dữ liệu từ phần mềm AMOS

Kết quả tính toán các hệ số hồi quy của các mối quan hệ trong mô hình giả thuyết cho thấy, các giả thuyết $\mathrm{H} 1, \mathrm{H} 2, \mathrm{H} 3, \mathrm{H} 4, \mathrm{H} 5, \mathrm{H} 7, \mathrm{H} 8, \mathrm{H} 9, \mathrm{H} 10$ được chấp nhận vì các mối quan hệ hồi quy trên có ý nghĩa thống kê với P-value nhỏ hơn 0,05 . Giả thuyết H6 không được chấp nhận vì $\mathrm{P}$-value lớn hơn 0,05 . Sau khi loại bỏ mối quan hệ của giả thuyết $\mathrm{H} 6$ và tính toán lần 2 các hệ số hồi quy, các tác giả xác định được ba phương trình hồi quy như sau: 
+ Phương trình 1: Các yếu tố ảnh hưởng tới Sụ hài lòng trong công việc (JS):

$$
\begin{gathered}
J S=0,391 * P B+0,187 * T D+169 * W C-0,150 * 147 * J C+0,142 * S S J S t+0, \\
\left(\text { Vó́i } R^{2}=0,717\right)
\end{gathered}
$$

+ Phương trình 2: Tác động của biến Hài lòng công việc (JS) đến Cam kết tổ chức $(O C)$ :

$$
\mathrm{OC}=0,690 * \mathrm{~J}\left(\text { Với } \mathrm{R}^{2}=0,476\right)
$$

+ Phương trình 3: Tác động của biến Hài lòng công việc (JS) và Cam kết tổ chức (OC) đến Ý định nghi việc (TI):

$$
\mathrm{TI}=-0,391 * \mathrm{JS}-0,377 * \mathrm{OC}\left(\text { Với } \mathrm{R}^{2}=0,499\right)
$$

Kiểm định Bootstrap cho thấy độ chệch giữa ước lượng mẫu và ước lượng bootstrap đạt giá trị cho phép (giá trị tới hạn nhỏ hơn 1,96), như vậy trong thực tế có thể ước lượng mẫu suy rộng cho tổng thể. Chỉ số C.R $<1,96$, suy ra p-value $>5 \%$, mô hình ước lượng được coi là đáng tin cậy.

\section{Thảo luận kết quả}

$72,9 \%$ sự thay đổi về Hài lòng trong công việc của nhân viên được giải thích bởi các yếu tố Bản chất công việc, Căng thẳng công việc, Chi trả và phúc lợi, Đào tạo và thăng tiến, Sự hỗ trợ của cấp trên, Môi trường làm việc. 48,6\% sự thay đổi trong Cam kết tổ chức được giải thích bởi sự Hài lòng công việc. 50,2\% sự thay đổi trong Ý định nghỉ việc của nhân viên kỹ thuật trong ngành đến từ sự kém hài lòng với công việc và sự ít cam kết với tổ chức của họ (độ tin cậy $95 \%)$.

Các khoản chi trả và phúc lợi có tác động lớn nhất đến sự hài lòng của nhân viên. Văn hóa Việt Nam nói riêng và Á Đông nói chung rất coi trọng vai trò trụ cột gia đình của nam giới. Họ được mặc định là những người bảo đảm cuộc sống cho người thân của mình. Với lực lượng nhân viên kỹ thuật hầu hết là nam giới, thu nhập là vô cùng quan trọng, có ý nghĩa về khả năng của một người đàn ông. Bên cạnh đó, tại TP.HCM, áp lực về các khoản chi tiêu cũng lớn hơn, nhu cầu trang trải cuộc sống lớn nên họ rất nhạy cảm với vấn đề chi trả. Kết quả này tương tự với các nghiên cứu của Kim và cộng sự (1996), Thatcher và cộng sự (2002), Nguyen (2014).

Công nghệ hiện nay luôn được cải tiến và sáng tạo. Đối với ngành nghề mang tính chất kỹ thuật, cá nhân hay doanh nghiệp đều phải chịu áp lực lớn trong cạnh tranh. Khách hàng thường sẽ lựa chọn những giải pháp hệ thống tối ưu về kỹ thuật và chi phí. Những người nổi trội, làm việc hiệu quả, sẽ được trọng dụng. Vì vậy, nếu được đào tạo và phát triển, sự hài lòng của nhân viên sẽ tăng lên. Kết quả này tương tự với các nghiên cứu của Kim và cộng sự (1996), Hoonakker và cộng sự (2013).

Sức ép về công việc luôn đè nặng lên vai của các kỹ thuật viên tại ngành này. Kết quả thống kê mô tả cho thấy, đa số nhân viên cảm thấy rất căng thẳng công việc, nếu kéo dài sẽ làm giảm sự hài lòng trong công việc. Kết quả này tương tự với các nghiên cứu của Kim và cộng sự (1996); Calisir và cộng sự (2011). 
Khi làm việc trong điều kiện bất lợi và khắc nghiệt lâu dài, sức khỏe chắc chắn bị ảnh hưởng. Bên cạnh đó, nếu thời gian làm việc quá nhiều, thời gian dành cho cuộc sống riêng bị hạn chế thì về lâu dài, sự căng thẳng, mâu thuẫn sẽ tăng và sự hài lòng sẽ giảm. Điều này phù hợp với nghiên cứu trước đây của Hoonakker và cộng sự (2013).

Bản chất công việc có tác động đến Sự hài lòng với mức độ không cao. Có thể là do một kỹ thuật viên thường được đào tạo khá rộng cho các công việc của một lĩnh vực cụ thể (Điện, Điện-điện lạnh, Điện tự động, $\mathrm{CNTT}, \ldots$.). Trong quá trình thực hiện công việc, các kỹ năng và kinh nghiệm thực tế đã được trau dồi nên nếu thay đổi công việc, họ vẫn có khả năng đáp ứng được yêu cầu sau một thời gian và dễ cảm thấy phù hợp.

Trong ngành dịch vụ hạ tầng CNTT, một đội-nhóm thi công thường thực hiện công việc trong một khoảng không gian tách biệt. Việc đánh giá hay nhận xét khả năng của một kỹ thuật viên hoàn toàn phụ thuộc vào cấp trên trực tiếp của họ (giám sát hoặc phó/trưởng phòng kỹ thuật). Những người này thường có tay nghề cao và hiểu biết nhiều về công việc nên cấp dưới có thể hy vọng rất nhiều về sự hỗ trợ. Nếu cấp trên hỗ trợ không tốt thì cấp dưới có thể giảm hài lòng trong công việc.

Kết quả kiểm định giả thuyết cho thấy sự hỗ trợ của đồng nghiệp không ảnh hưởng đến sự hài lòng trong công việc, mặc dù dữ liệu khảo sát cho thấy, đồng nghiệp hỗ trợ lẫn nhau khá tốt. Có lẽ là vì đại đa số các kỹ thuật viên là nam giới và thường có tính cách đơn giản, khá thoải mái nên ít quan tâm tới các vấn đề trong quan hệ đồng nghiệp hay những vấn đề nhỏ trong cuộc sống.

Sự hài lòng công việc càng cao thì mức độ cam kết tổ chức càng lớn, từ đó Ý định nghỉ việc càng ít đi. Kết quả nghiên cứu này là một điều dễ giải thích và tương tự với hầu hết các mô hình nghiên cứu trước đây. Kết quả tính toán cũng cho thấy, các biến tác động trực tiếp đến $J S$ còn tác động gián tiếp đến $O C$ thông qua $J S$, tác động gián tiếp đến $T I$ thông qua $J S$ và $O C$. Như vậy, nếu chúng ta điều chỉnh các yếu tố nhằm gia tăng Sự hài lòng trong công việc của nhân viên thì cũng sẽ gián tiếp làm tăng Cam kết tổ chức và giảm Ý định nghỉ việc của họ.

\section{Kết luận}

Nghiên cứu đã đạt được ba mục tiêu đặt ra là xác định được 6 yếu tố ảnh hưởng đến Hài lòng công việc, trong đó ảnh hưởng mạnh nhất là Chi trả; xác định được mức độ ảnh hưởng của Hài lòng công việc tới Cam kết tổ chức và ảnh hưởng của chúng tới ý định nghỉ việc của nhân viên kỹ thuật trong ngành dịch vụ hạ tầng CNTT.

Kết quả này phù hợp với kết quả của các nghiên cứu của Kim và cộng sự (1996); Hoonakker và cộng sự (2013); Calisir và cộng sự (2011); Thatcher và cộng sự (2002); Nguyen (2014).

Nghiên cứu cũng đưa ra một số hàm ý quản trị giúp các doanh nghiệp cung cấp dịch vụ hạ tầng CNTT tham khảo để tăng sự hài lòng của nhân viên kỹ thuật, tăng cam kết với tổ chức, đồng thời giảm thiểu ý định nghỉ việc.

Trước hết là cần chú trọng hơn tới các chính sách lương, thưởng phúc lợi, đặc biệt là chế độ bảo hiểm, vì ngành nghề kỹ thuật làm hao mòn sức khỏe nhanh, tỷ lệ bị tai nạn cao. Cần 
có các khoản thưởng xứng đáng mỗi khi hoàn thành công trình; các chính sách phúc lợi khác như du lịch hàng năm, thưởng lễ Tết, lương tháng 13 cần công bố rõ ràng.

Việc thiếu kỹ năng và kiến thức sẽ ảnh hưởng tới chất lượng và tiến độ công việc, làm nhân viên nản lòng và căng thẳng. Cần chú trọng việc đào tạo một đội ngũ kỹ thuật lành nghề - tạo lợi thế cạnh tranh của doanh nghiệp. Bên cạnh đó, cũng cần công khai lộ trình nghề nghiệp, có chương trình hoạch định kế thừa, hoạch định thay thế để khuyến khích nhân viên kỹ thuật nâng cao trình độ và phát triển bản thân.

Việc phải tăng ca để kịp tiến độ công trình, thời gian nghỉ ngơi không đảm bảo, các rủi ro về an toàn lao động và rủi ro phải đền bù nếu xảy ra thiệt hại, yêu cầu phải hoàn thành công việc một cách tỷ mỷ và chính xác, ... đã gây áp lực và tạo căng thẳng cho nhân viên kỹ thuật trong ngành, ảnh hưởng xấu đến sức khỏe tinh thần và thể chất về lâu dài. Vì vậy cần tạo sự cân bằng công việc - cuộc sống cho nhân viên, ví dụ áp dụng chế độ nghỉ phép linh hoạt, nghỉ bù thỏa đáng, phụ cấp tăng ca phù hợp. Ngoài ra cần chú ý tới đặc thù môi trường làm việc của ngành là rất khắc nghiệt để tăng cường an toàn và vệ sinh lao động, cung cấp trang thiết bị bảo hộ, tổ chức lớp học an toàn lao động.

Khi cần sự hỗ trợ của cấp trên mà không được đáp ứng, các nhân viên kỹ thuật sẽ không hài lòng, lo ngại không đạt hiệu suất và hiệu quả công việc ảnh hưởng đến tiến độ công việc chung. Vì vậy, cần đẩy mạnh việc đối thoại, tăng cường lắng nghe ý kiến nhân viên qua các buổi họp hay gặp gỡ cá nhân.

Nếu các vấn đề trên được giải quyết tốt thì theo kết quả nghiên cứu thể hiện, sự Hài lòng công việc và Cam kết tổ chức sẽ được cải thiện, từ đó giảm thiểu được Ý định nghỉ việc của nhân viên kỹ thuật trong ngành.

\section{Tài liệu tham khảo}

Allen, N. J., \& Meyer, J. P. (1990). The measurement and antecedents of affective, continuance and normative commitment to the organization. Journal of Occupational Psychology, 63(1), 1-18.

Baroudi, J. J. (1985). The impact of role variables on IS personnel work attitudes and intentions. MiS Quarterly, 9(4), 341-356.

Bidgoli, A. M., Moshref-Javadi, M. H., \& Ayobi, Z. (2013). The relationship between social capital and job stress case study: Airports administration of Isfahan Province, Iran. Journal of Basic and Applied Scientific Research, 3(4), 710-715.

Calisir, F., Gumussoy, C. A., \& Iskin, I. (2011). Factors affecting intention to quit among IT professionals in Turkey. Personnel Review, 40(4), 514-533.

Cook, J., \& Wall, T. (1980). New work attitude measures of trust, organizational commitment and personal need non-fulfilment. Journal of Occupational and Organizational Psychology, 53(1), 39-52. 
Gerbing, D. W., \& Anderson, J. C. (1988). An updated paradigm for scale development incorporating unidimensionality and its assessment. Journal of Marketing Research, 25(2), 186-192.

Hackman, J. R., \& Oldham, G. R. (1975). Development of the job diagnostic survey. Journal of Applied Psychology, 60(2), 159-170.

Hill, E. J., Grzywacz, J. G., Allen, S. M., Blanchard, V. L., Matz, C., Shulkin, S., \& PittCatsouphes, M. (2008). Defining and conceptualizing workplace flexibility. Community Work \& Family Work and Family, 11(2), 149-163. doi:10.1080/13668800802024678

Hoonakker, P., Carayon, P., \& Korunka, C. (2013). Using the job-demands-resources model to predict turnover in the information technology workforce-general effects and gender differences. Horizons of Psychology, 22, 51-65.

Humphreys, R. H. (2002). The many faces of emotional leadership. The Leadership Quarterly, 13(5), 493-504. doi:10.1016/S1048-9843(02)00140-6

Kanwar, Y. P. S., Singh, A. K., \& Kodwani, A. D. (2012). A study of job satisfaction, organizational commitment and turnover intent among the IT and ITES sector employees. Vision, 16(1), 27-35.

Kim, S. (2005). Factors affecting state government information technology employee turnover intentions. The American Review of Public Administration, 35(2), 137-156.

Kim, S.-W., Price, J. L., Mueller, C. W., \& Watson, T. W. (1996). The determinants of career intent among physicians at a U.S. Air Force hospital. Human Relations, 49(7), 947-976.

Luddy, N. (2005). Job satisfaction amongst employees at a public health institution in the Western Cape. Retrieved January 12, 2018, from http://etd.uwc.ac.za/xmlui/handle/11394/1418

Mobley, W. H. (1982b). Employee turnover: Causes, consequences, and control. Reading, MA: Addison-Wesley.

Mowday, R. T., Porter, L. W., \& Steers, R. M. (2013). Employee-organization linkages: The psychology of commitment, absenteeism, and turnover. Cambridge, MA: Academic press.

Nguyen, V. X. (2014). Anh hương của sụ thỏa mãn công việc đến dụ định nghi việc của lao động ngành CNTT tại TP.HCM [The impact of job satisfaction on the intention of leaving IT workers in Ho Chi Minh City]. (Unpublished doctoral dissertation). Trường Đại học Mở Thành phố Hồ Chí Minh, Vietnam.

Podsakoff, P. M., MacKenzie, S. B., \& Bommer, W. H. (1996). Transformational leader behaviors and substitutes for leadership as determinants of employee satisfaction, commitment, trust, and organizational citizenship behaviors. Journal of Management, 22(2), 259-298. doi:10.1016/S0149-2063(96)90049-5

Price, J. L., \& Mueller, C. W. (1981). A causal model of turnover for nurses. Academy of Management Journal, 24(3), 543-565.

Robbins, S. P. (2013). Organizational behavior. Karnataka, India: Pearson Education India. 
Thatcher, J. B., Stepina, L. P., \& Boyle, R. J. (2002). Turnover of information technology workers: Examining empirically the influence of attitudes, job characteristics, and external markets. Journal of Management Information Systems, 19(3), 231-261.

Tran, D. K. (2005). Đo lường mức độ thỏa mãn đối với công việc trong điều kiện của Việt Nam [Measuring job satisfaction in Vietnamese conditions]. Tạp chí Phát triển Khoa học, 8(1), $1-9$.

VietnamWorks. (2015). Ngành Công Nghệ Thông Tin Việt Nam thiếu hụt số lương nhân sụ khổng lồ [The Vietnam Information Technology industry lacks a huge number of employees]. Retrieved March 20, 2018, from https://hrinsider.vietnamworks.com/nganhcong-nghe-thong-tin-viet-nam-thieu-hut-so-luong-nhan-su-khong-lo.html 